Elizabeth Kent ${ }^{1}$, Scott Woodruff², Nick Rayner ${ }^{3}$, Chris Folland ${ }^{3}$, David Parker ${ }^{3}$, Dick Reynolds ${ }^{4}$ and Takashi Yoshida ${ }^{5}$

1: National Oceanography Centre, Southampton., 2: NOAA, Earth System Research Laboratory., ${ }^{3:}$ Met Office, Exeter. , 4: NOAA, National Climatic Data Center., 5: Japan Meteorological Agency

The 2nd International Workshop on Advances in the Use of Historical Marine Climate Data (MARCDAT-II) was hosted by the Met Office, Exeter, UK from 17-20 October 2005. This was the latest in a series of marine workshops held approximately every two years since 1999. MARCDAT (in Boulder 2002 and Exeter 2005) alternates with 'CLIMAR' Workshops on Advances in Marine Climatology (in Vancouver 1999 and Brussels 2003).

These workshops have brought together a wide spectrum of marine data users, and managers of marine data and products, and have included an underlying focus on the continuing evaluation, utilization, and improvement of the International Comprehensive Ocean-Atmosphere Data Set (ICOADS, Worley et al. 2005). In addition to published outcomes (including Diaz et al. 2002, WMO 2003, Parker et al. 2004) the previous workshops have produced and actively tracked a consolidated set of scientific and technical recommendations [icoads.noaa.gov/marcdat2] to help guide the work of this group and provide feedback for the broader research community.

MARCDAT-II attracted more than 60 participants from eight countries for four days of oral presentations, posters and discussion. On the 21 October two more related meetings were held, of the Global Climate Observing System Working Group on Sea Surface Temperature and Sea Ice, and the Working Group on Surface Pressure.

\section{Workshop Goals}

The overall aim of the meeting was "To set priorities for the future development of marine climate data and products over the next four years". The meeting had four specific goals, to: (1) develop the timetable for enhancing in situ marine data bases, with a focus on ICOADS, taking account of plans for further digitization and improved processing of the basic observational data; (2) develop strategies for the creation of multi-decadal, homogeneous, gridded data sets for climate applications, and identify priorities for improvement in particular variables; (3) discuss methods for quantifying uncertainties in marine data and create a timetable for the assembly of a suite of gridded marine datasets with associated uncertainties; (4) consider how to define future data requirements.

\section{Presentations}

Following a review of progress on the consolidated recommendations, invited and contributed presentations covered subjects including: the reconstruction of ship routes from periods before longitude was measurable; reports on major new data recovery and digitisation projects; new methods for the construction of surface flux datasets using probability distributions; investigating the possibility of generating 100 years of daily reanalysis products with uncertainties similar to those in modern 2 to 3 day forecasts; integrating in situ and remotely-sensed data to produce long climate-quality time series; the effect of dataset reconstruction techniques on climate change estimates; assessments of the adequacy of the surface marine climate observing system; and future plans for the development of the ICOADS.

\section{Discussion and Recommendations}

Discussions were held in small groups each focussing on a range of marine variables.

An overarching recommendation was for continuing augmentation of ICOADS with in situ marine meteorological data, and enhanced links to ocean data repositories, such as the World Ocean Database. Perhaps 25 million undigitised data exist for instance in United Kingdom national archives. In view of scarce resources, the need for data inventories and assessments to help identify priorities for digitisation and datasets for incorporation into ICOADS was also highlighted.

Concern was expressed that the marine observation system is in decline. Observations from Voluntary Observing Ships (VOS) have reduced by more than a half since 1990 and we now have less than a third of the number of VOS participating in the program. As a result the uncertainty of in situ surface products is increasing. All of the discussion groups were concerned about the diminishing data quantities, which represent a huge challenge for the future. It is essential that the marine climate community make assessments of its future data requirements and feed this information through to the appropriate operational bodies.

The availability of comprehensive metadata on observational method for all observation platforms was thought to be key to the production of high quality datasets.

The importance of improving communication between scientists and both marine observers and operational centres was stressed.

The need for the production of a variety of well-documented gridded datasets for all marine variables, developed using a range of techniques, is essential to understand biases, structural uncertainties and the impacts of QC and analysis procedures. A number of concrete plans to achieve this were discussed.

The workshop felt that there was much to be gained from regular intercomparisons of datasets produced in near real time and for the continued use of multivariate techniques to improve marine datasets.

Although MARCDAT-II identified large efforts still needed to improve marine climatology, the progress since the first CLIMAR meeting in 1999 is impressive and we look forward to the next in this unique series of productive meetings in 2007.

\section{Further Information}

Presentations, meeting outcomes and the full set of recommendations will be published on the MARCDAT website (icoads.noaa.gov/marcdat2/).

\section{References}

Diaz, H., C. Folland, T. Manabe, D. Parker, R. Reynolds, and S. Woodruff, 2002: Workshop on Advances in the Use of Historical Marine Climate Data. WMO Bulletin, 51(4), 377-380.

Parker, D., E. Kent, S. Woodruff, D. Dehenauw, D.E. 
Harrison, T. Manabe, M. Mietus, V. Swail, and S. Worley, 2004: The Second JCOMM Workshop on Advances in Marine Climatology (CLIMAR-II). WMO Bulletin, 53(2), 157-159.

WMO, 2003: Proceedings of CLIMAR99-WMO Workshop on Advances in Marine Climatology, Vancouver,
Canada, 1999, JCOMM Technical Report No. 13-CDROM.

Worley, S.J., S.D. Woodruff, R.W. Reynolds, S.J. Lubker, and N. Lott, 2005: ICOADS Release 2.1 data and products. Int. J. Climatol., 25, 823-842.

\section{Report of the CLIVAR/00PC/G00S/Argo/CPPS Workshop on the South Pacific}

\section{A. Caltabiano, ICPO}

National Oceanography Centre, Southampton, UK, email: icpo@noc.soton.ac.uk

What drives decadal variability in the South Pacific and to what extent can it be predicted? What fraction of decadal variability in the South Pacific is connected with ENSO? What factors influence the ocean/atmosphere interactions that drive changes in the subtropical cell? Is the observing system in the South Pacific adequate in monitoring oceanic and atmospheric features in the region? These were some of the questions addressed at the CLIVAR/OOPC/ GOOS/Argo/CPPS workshop on the South Pacific, held at the University of Concepción (UdeC), Chile, on 11-14 October 2005. The workshop had a very good attendance with 59 participants from 13 different countries, and was structured around fours sessions on Climate, Regional Impacts, Prediction and Predictability, and the Observing System. There was also a special session dedicated to the Argo Programme, and the impact it has had on monitoring the South Pacific.

One of the issues discussed relates to the air-sea interaction in the South Pacific, the need to examine this and its importance in underpinning statistical and dynamical forecast systems. This is an area where collaboration among CLIVAR's Pacific Panel, the Variability of the American Monsoon System (VAMOS) Panel, and the Working Group on Seasonal to Interannual Prediction (WGSIP) is desirable, to address, for example, the inter-relationships between tropical and Central South Pacific (CSP) SSTs and atmospheric changes over South America.

Two particular process studies in the Pacific area of great relevance to the South Pacific were presented. The first was the Pacific Upwelling and Mixing Physics (PUMP), which is being organized under US CLIVAR and is designed to improve the understanding of the variety of mechanisms that connect the thermocline to the surface in the equatorial Pacific cold tongue. Its goal is to observe and understand the interaction of upwelling and mixing with each other and with the larger-scale equatorial current system. The outcome of PUMP will be advancements in our ability to diagnose and model both the mean state of the coupled climate system in the tropics and its interannual and interdecadal variability. The second study was the Southwest Pacific Circulation and climate Experiment (SPICE).SPICE is aimed at a regional study of (i) bifurcation of the south equatorial current on the coast of Australia, (ii) the role of the east Australia current for the region, (iii) circulation in the North Coral Sea and includes a module on impacts and outreach. Both projects are still in the planning stages but were strongly encouraged to continue to pursue funding due to their importance for the South Pacific region and our understanding of ocean processes more generally.
Argo was discussed at considerable length. It was noted that there are considerable gaps in the current deployment for the South Pacific but those areas are being targeted for deployments by the US Argo program. The University of Concepción presently has 30 profiling floats in their inventory, some of which include dissolved oxygen sensors. Because the areas targeted by UdeC might have some overlap with the ones targeted by US, it was noted that a close interaction between those involved, with oversight by the Argo Program, was needed. Other deployment strategies were discussed and offers were made by representatives of Peru, Chile Ecuador and Colombia to assist with deployments for the completion of the global array.

All the other components of the observing system in the South Pacific were reviewed, with some important contributions on the efforts of the Pacific Island GCOS, and on data mining and data management. Considerable discussion also centred on the utility of gliders equipped with CTDs to sample the strong currents in the coastal zone. This discussion also noted that Argo is not very well suited to monitoring flow in boundary currents, but gliders are ideally suited. Gliders are poorly suited to sampling many locations in distant parts of the ocean, so there appears to be complementary features between these two systems.

It was also noted that the VAMOS Ocean-CloudAtmosphere-Land Study (VOCALS), which is presently in the planning stages of its field mission, will certainly provide a better understanding of the southeastern Pacific (SEP) coupled ocean-atmosphere-land system, on diurnal to interannual timescales. However, it was felt that VOCALS is very much focused on the marine boundary layer and clouds, therefore there is a strong need for a more sustained and coordinated effort to improve the monitoring of the eastern boundary current in the Southeastern Pacific. It was recommended that a small group could lead the task in gathering information on all the existing oceanographic observations in this region, to consider if there is a need of an additional sustained program that would enable a long term study of the eastern boundary current's impact on the South American continent.

The organising committee is very grateful to all the support provided by WCRP, US CLIVAR, GOOS/OOPC and Argo, which enabled key participants to attend the workshop. It also would like to thank the local support from the Center for Oceanographic Research in the Eastern South Pacific (COPAS), and the Department of Geophysics (DGEO) of the Faculty of Physical Sciences and Mathematics, University of Concepción. Presentations from the workshop can be found at: www.clivar.org/organization/pacific/implementation/ south_pac_workshop/south_pac.html 